\title{
Spontaneous tubal re-canalisation: A late complication of Falope ring sterilisation
}

\author{
Jeremy Twigg, MRCOG, MD, Specialist Registrar in Obstetrics and Gynaecology; Janet Evans, FRCOG, MRACOG, FRCS, \\ Consultant Obstetrician and Gynaecologist, Department of Gynaecology, University Hospital of Wales and Llandough \\ Hospital NHS Trust, Penarth, Vale of Glamorgan, Wales.
}

Correspondence: Janet Evans, Consultant Obstetrician and Gynaecologist, Department of Gynaecology, University Hospital of Wales and Llandough Hospital NHS Trust, Penlan Road, Penarth, Vale of Glamorgan, Wales, CF64 2XX.

(Accepted 30 March, 2001)

The Journal of Family Planning and Reproductive Health Care 2001: 27(3): 156-157

\begin{abstract}
The case presented demonstrates the possibility of late failure of laparoscopic female sterilisation due to migration of a Falope ring with tubal recanalisation as a possible mechanism.
\end{abstract}

\section{Key message points \\ - Late failure of laparoscopic falope ring sterilisation is rare \\ - Migration of Falope rings is described. \\ - Tubal re-canalisation is a potential mechanism}

\section{Case report}

A 37-year-old female was referred in September 1999 by her general practitioner with 5 weeks amenorrhoea and a 2-day history of worsening abdominal pain with vaginal bleeding. Clinical assessment revealed a soft, non-tender abdomen, blood in the vagina and a closed cervix. A hospital pregnancy test for human chorionic gonadotrophin (HCG) was positive at greater than $50 \mathrm{iU} / \mathrm{L}$. The next morning the pain had settled along with the bleeding. A transvaginal ultrasound scan showed an empty uterus with an endometrium measuring $4.9 \mathrm{~mm}$. There was no demonstrable free fluid in the pouch of Douglas, nor were there any adnexal masses visible. It was noteworthy that the patient had been sterilised 7 years previously. A diagnosis of complete miscarriage was made, and follow-up was arranged to discuss future contraception.

At gynaecology outpatients the patient reported that she had had a subsequent menstrual period since admission. She requested a second sterilisation procedure and was started on the combined oral contraceptive pill until the operation date. A review of the hospital notes revealed that the patient had previously undergone a laparoscopic Falope ring sterilisation undertaken by a consultant gynaecologist.

During the second laparoscopic sterilisation procedure in January 2000 the Falope ring on the left fallopian tube was seen and appeared to be occluding the cornual segment of tube (Figure 1 Panel $\mathrm{A}$ and $\mathrm{C}$ ). The right Falope ring, however, could be seen below the cornual portion of tube within the mesosalpinx (Figure 1 Panel B and D). It was concluded from the visual inspection that the tube must have spontaneously recanalised following migration of the Falope ring into the mesosalpinx. A Filshie clip was applied to each tube for the second sterilisation procedure.

\section{Discussion}

The use of the Falope ring was first described by Yoon in
1974 as an alternative technique for sterilisation at a time when laparoscopic electrocautery was in widespread use. ${ }^{1}$ It was reported to reduce complication rates compared to unipolar diathermy and enhance pregnancy rates for those women requesting reversal. ${ }^{2}$ Furthermore, the success rate of this method of sterilisation has been confirmed by several studies from different parts of the world and it is thus used widely in gynaecological practice. ${ }^{3,4}$ Moreover, the rate of tubal patency following this method of sterilisation is low, and if patency is demonstrated postprocedure it does not appear to lead to pregnancy. ${ }^{3}$

Following this case we undertook a literature search using Medline for the years 1966-2000 for articles relating to Falope ring sterilisation, to determine failure rates per method and to ascertain mechanisms for failure. The largest study to date examining sterilisation failure was reported by Peterson et al in $1996 .^{5}$ The CREST data reveal that failure rates for different methods of sterilisation vary widely between 7.5 and 36.5 per 1000 procedures after 10 years. Other factors, including age at sterilisation and race, also appear to influence the failure rate..$^{5}$ According to Peterson's data our patient could have expected a cumulative risk of pregnancy during the seventh post procedure year of 13 per 1000 (confidence interval 3.4-22.5).

The data on the mechanisms for failure are less well understood. Early failure of sterilisation is primarily thought to occur in association with incorrect application of the ring at the primary procedure, and this type of failure is is most likely to happen within the first year. ${ }^{6,7}$ Later failure is more likely to be associated with recanalisation of the fallopian tube. ${ }^{8}$ Migration of occlusive clips such as the Filshie as a potential mechanism for late recanalisation has recently been proposed by a report in this journal. ${ }^{9}$ This case report is noteworthy with regard to the Falope ring as, to our knowledge, it is the first to confirm that these silicone bands may also migrate, thus allowing spontaneous recanalisation and the risk of subsequent pregnancy.

\footnotetext{
Statements on funding and competing interests

Funding: None.

Competing interests: None.

Acknowledgements

Dr Karl Johansen

References

King TM. The laparoscopic Falope ring technique. Advances in Planned Parenthood 1975; 10: 154-159.

Chatman DL. Laparoscopic Falope ring sterilisation. Two years of experience. American Journal of Obstetrics and Gynaecology 1978; 131: 291-294.

Cook CL. Evaluation of falope ring sterilization by hysterosapingogram. Journal of Reproductive Medicine 1982; 27: 243-248.

Hertz JB. Laparoscopic sterilisation with the Falope ring technique. Acta Obsterrica et Gynaecologica Scandanavia 1982; 61: 13-15.

Peterson HB, Xia Z, Hughes JM, et al. The risk of pregnancy after tubal sterilisation: Finding from the U.S. Collaborative Review of Sterilisation. American Journal of Obstetrics an Gynaecology 1996; 174: 1161-1170.

6 Pattinson RC, Louw NS, Engelbrecht B, et al. Complications in 8509 laparoscopic falope ring sterilisations performed under local anaesthesia. South African Medical Journal 1983; 64: 974-976.
} 
Figure 1 Panel $A$ and $C$ : images at times of surgery. Arrows identify Falope rings. Panel B and D: sketches to show position of Falope ring $(F)$ in relation to Uterus (U), Ovary $(O)$ and Fallopian Tube (FT)
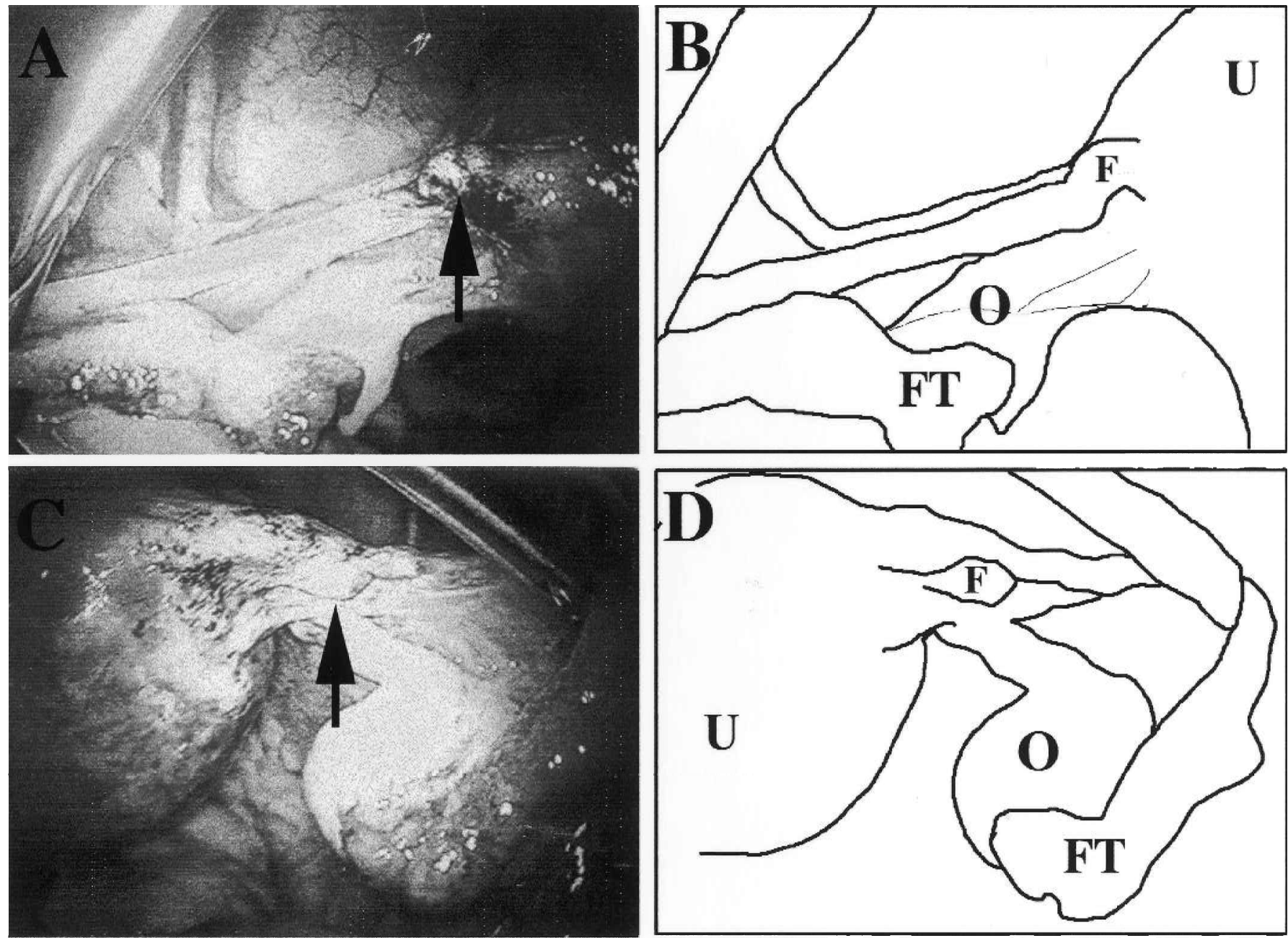

Stovall TG, Ling FW, Henry GM, et al. Method failures of laparoscopic tubal sterilisation in a residency training program. A comparison of the tubal ring and spring loaded clip. Journal of

Reproductive Medicine 1991; 36: 283-286.
Guillebaud J. Correspondence on Contraceptives. Bandolier June 1998; 52: 8 .

Amu O, Husemeyer RP. Migration of sterilisation clips: case report and review. British Journal of Family Planning 1999; 25: 27-28. 